\title{
Dispersal of Abdominal Visceral; Subcutaneous, Visceral to Subcutaneous Adiposity Ratio and Metabolic Syndrome in A Sample of Obese Egyptians
}

\author{
Nayera E. Hassan, Mohamed S. El Hussieny, Enas Abdel Rasheed, \\ and Sahar A. El-Masry
}

\section{ABSTRACT}

Background: Visceral to subcutaneous adiposity ratio (VSR) may be more crucial than visceral and subcutaneous adipose tissue per se. It reflects relative distribution of abdominal adiposity which is a better indicator of cardio-metabolic risk.

Aim: to examine if the VSR has diagnostic value in identifying metabolic syndrome (MS) compared with VAT and SAT among sample of obese Egyptians.

Subjects and Methods: The over here study included 456 obese Egyptian adults (106 male and 350 female), ageing across 25- 55 years. All participants subjected to blood pressure and anthropometric assessment, abdominal ultrasound, and laboratory tests.

Results: Males had quite high level of triglycerides and low HDL than females, who had significantly higher frequency of wide WC than men. There was insignificant sex difference in the frequency of MS. VAT and SAT were significantly higher in presence of wide WC and hypertension among both sexes. Also, VSR was significantly higher in presence of wide WC and hypertension among women only. While presence of MS led to significantly higher value of SAT among men, and VAT among women. Area under the curves (AUCs) for VAT, SAT and VSR; to predict MS; were $0.59,0.63$ and 0.46 among men and $0.63,0.56$ and 0.55 among women.

Conclusion: Visceral and subcutaneous adipose tissue; not visceral/subcutaneous ratio; were significantly affected by the presence of MS in both sexes. SAT was significantly superior among men, while VAT was superior among women. VSR cannot be used as a predictor of MS.

Keywords: Adiposity, Egyptians, metabolic, obesity, subcutaneous, syndrome, visceral.

\section{INTRODUCTION}

Obesity is a crucial globalized medical condition. It is linked with several cardio-metabolic risk factors including dyslipideamia, hypertension, insulin resilience and category 2- diabetes. Research demonstrated that it is a heterogeneous problem with some obese individuals being metabolically healthy, which may be clarified by the disparity of regional fat distribution within subjects [1].

The type of body fat distribution is deemed the most significant factor for obesity, cardiovascular diseases, and metabolic syndrome [2]. Plenty of visceral adiposity is correlated with the occurrence of metabolic health diseases regardless generalized obesity [3]. Moreover, the subcutaneous adipose tissue may have a valuable role against metabolic diseases [4].

The dispensation of abdominal adiposity may be more essential than visceral and subcutaneous adiposity per se as their ratio is more forcefully linked to the danger of
Published Online: December 2,2021

ISSN:2736-5476

DOI: $10.24018 /$ ejclinicmed.2021.2.6.124

N. E. Hassan

Biological Anthropology Department, Medical Research Division, National Research Centre, Dokki, Giza, Egypt. M. S. El Hussieny

Biological Anthropology Department, Medical Research Division, National Research Centre, Dokki, Giza, Egypt.

E. Abdel Rasheed

Clinical and Chemical Pathology Department, Medical Research Division, National Research Centre, Cairo, Egypt

S. A. El-Masry*

Biological Anthropology Department, Medical Research Division, National Research Centre, Dokki, Giza, Egypt. (e-mail: masrysa@yahoo.com)

*Corresponding Author cardiovascular disease [4]. Also, VSR has been contemplated to be a superior indicator of cardio-metabolic hazard not only in the asymptomatic and obese subjects but also in subjects with category 2 DM [3].

The visceral and subcutaneous adipose tissue may be evaluated by using imaging modalities like as computerized tomography (CT), magnetic resonance imaging (MRI) and ultrasound modality. CT is the most used method, but it involves exposure to ionizing radiation besides its high outlay. MRI, besides its high cost and low availability, needs a long time for obtaining images, which represents a sizable limitation [2].

Ultrasound is an accurate and sensitive measurement tool. It is reviewed as one of the most hopeful methods for measuring adipose tissue layers in the body [5].It can be used to assess visceral and subcutaneous adipose tissue with a sensibility not achieved by other method [6]. In contrast to $\mathrm{CT}$ and MRI limitations, US have been establishing a simple, low-cost tool, free of radiation risk with repeatability and 
reliability already certified in the appraisal of visceral and subcutaneous adiposity [7].

\section{A. Aim of the Work}

To collate the role of visceral, subcutaneous, and visceralto-subcutaneous adiposity ratio (VSR) as a diagnostic marker in identifying metabolic jeopardy associated with metabolic syndrome among sample of obese Egyptians.

\section{SubJeCTS AND Methods}

\section{A. Study Subjects}

This retrospective cross-sectional study included 456 obese Egyptian adults (106 males and 350 females), ageing between 25-55 years, selected from a scrutiny for appraisal of "Visceral and Central Obesity as an Early Estimator for Obesity Health Risk: Management and Intervention". Their BMI was more than $30 \mathrm{Kg} / \mathrm{m}^{2}$.Subjects with deficient medical histories with chronic illness apart from hypertension or diabetes was excluded. These subjects were enlisted from the staff member in the "National Research Centre"; situated in Giza governorate. Participators had informed about the aim of the investigation and their concert was gained. The memorandum was adopted by the "Ethical Committee" of the "National Research Centre". The numeral assent is 10/119.

\section{B. Methods}

All selected participants subjected to blood pressure and anthropometric evaluation, abdominal ultrasound, and laboratory tests.

\section{1) Blood Pressure}

Blood pressure was evaluated following resting 10 minutes using an automatic machine (BP-8800C; Colin Electronics Co., Ltd., Aichi, Japan). The estimation was repeated if the systolic pressure was $>130 \mathrm{mmHg}$ or the diastolic pressure was $>85 \mathrm{mmHg}$ with the average values recorded.

\section{2) Anthropometric Evaluation}

Anthropometric measurement was performed by trained personnel. Height, weight, waist, and hip circumferences were estimated following the proposal of the International Biological Program [8]. Height was estimated using the nearby $0.1 \mathrm{~cm}$ by a Holtain portable anthropometer, and weight was documented to the nearest $0.01 \mathrm{~kg}$ by a Seca Scale Balance, with the participant dressing minimum outfit and without footwear. Waist circumference was elicited opposite the umbilical plane when the participant is upright, relaxed and respiring regularly utilizing documented tape to the nearby $0.1 \mathrm{~cm}$. Then, Body mass index was measured utilizing the coming equation:

$$
\mathrm{BMI}=\left(\mathrm{WT} \mathrm{Kg} / \mathrm{HT} \mathrm{m}^{2}\right)
$$

Where BMI describes body mass index, HT describes height and WT stands for weight.

Normal BMI was specified as less than $25 \mathrm{~kg} / \mathrm{m}^{2}$, overweight as BMI $>25 \mathrm{~kg} / \mathrm{m}^{2}$ and obesity as BMI $>30 \mathrm{~kg} / \mathrm{m}^{2}$ for both males and females [9].

\section{3) Abdominal Ultrasound}

Ultrasound assessment of abdominal fat is done at the level of umbilicus by using the "Medison Sonoace X8" ultrasonography equipment. For visceral fat measurement, a 3.5 $\mathrm{MHz}$ probe was located at midline of the abdomen in transverse plane $1 \mathrm{~cm}$ above the umbilicus without any significant pressure. Visceral fat thickness documented as the interval between the posterior border of the rectus abdominis muscle and the anterior border of the aorta throughout exhalation. These measurements were built on previous technical designation [10].

\section{4) Laboratory Tests}

Blood samples were collected and analyzed from all participants after fasting for at least 12 hours. The supernatant serum was stored at $-80^{\circ} \mathrm{C}$ until analysis time. Plasma concentrations of cholesterol [11], triglycerides [12], and high-density lipoprotein-cholesterol (HDL-C) [13] were estimated utilizing kits manufactured by STANBIO Laboratory Inc.(1261 North Main Street Boerne Texas 78006 USA). Then total cholesterol/ HDL-C ratio was calculated. LDL-C was documented by using formula postulated by [14] as follows:

\section{LDL-C $=$ Total cholesterol - Triglycerides/5+ HDL-C.}

\section{a) Definition of metabolic risk factors}

Metabolic problems in our sample were categorized according to International Diabetes Federation, [15] criteria and included: systolic pressure $\geq 130 \mathrm{~mm} \mathrm{Hg}$ or diastolic pressure $\geq 85 \mathrm{~mm} \mathrm{Hg}$, FPG $\geq 100 \mathrm{mg} / \mathrm{dL}$, TG levels $\geq 150$ $\mathrm{mg} / \mathrm{dl}$, and HDL-C levels $<40 \mathrm{mg} / \mathrm{dL}$ for male and $<50 \mathrm{mg} / \mathrm{dL}$ for female. Metabolic syndrome was specified by two or more fore-mentioned changes.

\section{Statistical Analysis}

All mathematical scrutiny was conducted with the Statistical Package for Social Sciences (SPSS/Windows Version 18, SPSS Inc., Chicago, IL, USA). $P$-values of the outcome were two-tailed, and the relevance level was set at $P>0.05$. To equate the popular specifics, the continuous variables were stated as means \pm standard deviations and compared through independent $t$-test. The emphatic parameter was stated as percent and matched by utilizing the chi square test. Then, the participants were partitioned into two categories regarding risk factors (wide WC, increased glucose level, elevated BP, elevated TG, and decreased HDL cholesterol). As a minimum, three metabolic risk factors should be recorded for the diagnosis of metabolic syndrome. Disparities in mean VAT, SAT and VSR between each two categories regarding to metabolic syndrome risk factors were analyzed by independent $t$-test for each sex separately. The predictive accuracy of VFA, SFA, and VSR in determining persons with metabolic syndrome was assessed. Then, area under curve (AUC) was utilized to calculate the accuracy of each test.

\section{RESUlts}

Initiation specifics of study participants (table 1) revealed insignificant differences in age between men and women $(43.98+8.98$ and $43.41 \pm 9.41$ respectively).Likewise, negligible sex differences in DBP, WC, FBS, cholesterol, HDL, LDL, and subcutaneous fat. However, women had 
significantly increased values of SBP and BMI; while men had significantly increased values of triglycerides, visceral fat and VSR. Compared to females, males had significantly higher prevalence of high triglycerides and low HDL, and insignificant higher frequency of hyperglycemia and MS (Table II). However, women had significantly higher frequency of wide WC, and insignificant higher frequency of hypertension. In spite of insignificant sex difference in the frequency of MS, $28.3 \%$ of men and $25.4 \%$ of women had 3 risk factors of MS, $9.4 \%$ and $10.9 \%$ had 4 risk factors of MS, and $3.8 \%$ and $1.1 \%$ had 5 risk factors of MS respectively.

Comparisons between mean $\pm \mathrm{SD}$ of visceral, subcutaneous and visceral/subcutaneous fat ratio by metabolic risk factors revealed that visceral and subcutaneous fat were significantly higher in presence of wide $\mathrm{WC}$ and hypertension among both sexes. Also, visceral/subcutaneous fat ratio was significantly higher in presence of wide WC and hypertension among women only. While presence of MS led to significantly higher value of subcutaneous fat among men, and visceral fat among women. Moreover, subcutaneous fat was significantly higher in presence of hyperglycemia and increased triglycerides among men (Table III).

Area under the curves (AUCs) for VF, SF and VSR to predict MS were 0.59 (95\% CI 0.479-0.699), 0.63 (95\% CI $0.522-0.734), 0.46$ (95\% CI 0.352-0.575) among males 0.63 (95\%CI $0.571-0.689$ ), 0.56 (95\% CI $0.493-0.618), 0.55$ (95\% CI 0.489-0.615) among females. In males, subcutaneous fat exceeding VF $(\mathrm{P}<0.025)$, but visceral fat was superior to subcutaneous fat $(\mathrm{P}<0.000)$ among women. (Fig. 1 and table IV).

\begin{tabular}{ccccc}
\hline \hline Variables & $\begin{array}{c}\text { Men } \\
(\mathrm{N}=106) \\
\text { Mean } \pm \mathrm{SD}\end{array}$ & $\begin{array}{c}\text { Women } \\
(\mathrm{N}=350) \\
\text { Mean } \pm \mathrm{SD}\end{array}$ & $\mathrm{Z}$ & $\mathrm{P}$ \\
\hline Age (years) & $43.9 \pm 8.9$ & $43.4 \pm 9.4$ & -0.476 & 0.634 \\
Blood & & & & \\
pressure(mmHg) & & & & \\
SBP & $123 \pm 15.4$ & $128 \pm 19.1$ & -1.967 & $0.049 *$ \\
DBP & $81.8 \pm 11.3$ & $83.4 \pm 11.9$ & -1.039 & 0.299 \\
Anthropometry & & & & \\
BMI (Kg/m & $33.02 \pm 7.58$ & $37.57 \pm 7.13$ & -6.579 & $0.000^{* *}$ \\
WC (Cm 0 & $104.8 \pm 19.1$ & $104.2 \pm 13.9$ & -0.315 & 0.753 \\
Lab: & & & & \\
FBS (mg/dl) & $102.8 \pm 37.9$ & $103.7 \pm 37.9$ & -0.260 & 0.795 \\
Triglycerides & $163.6 \pm 93.4$ & $121.7 \pm 55.4$ & -3.621 & $0.000 * *$ \\
(mg/dl) & & & & \\
Cholesterol & $204.1 \pm 45.2$ & $201.4 \pm 48.5$ & -1.187 & 0.235 \\
(mg/dl) & $57.8 \pm 35.2$ & $53.6 \pm 24.6$ & -0.769 & 0.442 \\
HDL (mg/dl) & $122.7 \pm 42.3$ & $129.2 \pm 45.4$ & -1.107 & 0.268 \\
LDL (mg/dl) & & & & \\
US findings & & $6.2 \pm 2.2$ & -3.710 & $0.000^{* *}$ \\
VF umbilicus (cm) & $7.2 \pm 2.5$ & $2.7 \pm 1.4$ & -1.167 & 0.243 \\
SF umbilicus (cm) & $2.5 \pm 1.1$ & $2.6 \pm 1.2$ & -4.148 & $0.000^{* *}$ \\
\hline VSRumbilicus (cm) & $3.1 \pm 1.2$ & & & \\
\hline \hline
\end{tabular}

TABLE II: FREQUENCY DISTRIBUTION OF THE METABOLIC SYNDROME RISK FACTORS BY SEX

\begin{tabular}{ccccccc}
\hline \hline \multirow{2}{*}{ Variables } & $\begin{array}{c}\text { Metabolic } \\
\text { components }\end{array}$ & \multicolumn{2}{c}{$\begin{array}{c}\text { Men } \\
(\mathrm{N}=106)\end{array}$} & \multicolumn{2}{c}{$\begin{array}{c}\text { Women } \\
(\mathrm{N}=350)\end{array}$} & \multirow{2}{*}{$\begin{array}{c}\text { Chi }- \\
\text { square }\end{array}$} \\
\cline { 3 - 5 } & $\mathrm{N}$ & $\%$ & $\mathrm{~N}$ & $\%$ & \\
\hline High BP & $\geq 140 / 90 \mathrm{mmHg}$ & 30 & 28.3 & 135 & 38.6 & 0.065 \\
Hyper- & $\geq 100 \mathrm{mg} / \mathrm{dL}$ & 54 & 50.9 & 165 & 47.1 & 0.419 \\
glycemia & & 42 & 39.6 & 92 & 26.3 & $0.004^{* *}$ \\
High TG & $\geq 150 \mathrm{mg} / \mathrm{dL}$ & 22 & 20.8 & 45 & 12.9 & $0.040^{* *}$ \\
Low HDL & $<40 \mathrm{mg} / \mathrm{dL}$ & 22 & & & \\
Wide WC & $\geq 88 \mathrm{~cm}($ women $)$ & 64 & 60.4 & 320 & 91.4 & $0.00^{* *}$ \\
& $\geq 102 \mathrm{~cm}(\mathrm{men})$ & & & & & \\
MS & $\geq 3$ Risk Factors & 44 & 41.5 & 131 & 37.4 & 0.449 \\
& 3 Risk Factors & 30 & 28.3 & 89 & 25.4 & \\
& 4 Risk Factors & 10 & 9.4 & 38 & 10.9 & \\
& 5Risk Factors & 4.0 & 3.8 & 4.0 & 1.1 & \\
\hline \hline
\end{tabular}

TABLE I: DESCRIPTIVE STATISTICS OF THE STUDY PARTICIPANTS ACCORDING TO SEX (MANN-WHITNEY TEST)

TABLE III: COMPARISONS BETWEEN MEAN — SD OF VISCERAL, SUbCUTANEOUS AND ViSCERAL/SUBCUTANEOUS FAT RATIO BY METABOLIC RiSK FACTORS

\begin{tabular}{|c|c|c|c|c|c|c|}
\hline \multirow{3}{*}{ Variables } & \multicolumn{3}{|c|}{ Men $(\mathrm{N}=106)$} & \multicolumn{3}{|c|}{ Women $(\mathrm{N}=350)$} \\
\hline & Absent & Present & P-value & Absent & Present & P-value \\
\hline & Mean \pm SD & Mean \pm SD & & Mean + SD & Mean \pm SD & \\
\hline \multicolumn{7}{|l|}{ VF umbilicus $\left(\mathrm{cm}^{2}\right)$} \\
\hline High BP & $6.5 \pm 2.3$ & $8.3 \pm 2.4$ & 0.001 & $5.7 \pm 1.9$ & $6.8 \pm 2.2$ & 0.000 \\
\hline Hyperglycemia & $6.6 \pm 2.4$ & $7.7 \pm 2.4$ & 0.066 & $6.1 \overline{3}+2.2$ & $6.3+2.1$ & 0.555 \\
\hline High TG & $6.8 \pm 2.6$ & $7.7 \pm 2.5$ & 0.124 & $6.0 \pm 2.1$ & $6.6 \pm 2.2$ & 0.103 \\
\hline Low HDL & $7.1 \pm 2.6$ & $7.5 \pm 2.3$ & 0.444 & $6.2 \pm 2.2$ & $6.2 \pm 2.1$ & 0.918 \\
\hline Wide WC & $5.8 \pm 2.1$ & $8.1 \pm 2.3$ & 0.000 & $4.0 \pm 1.5$ & $6.4 \pm \underline{2} .1$ & 0.000 \\
\hline MS & $6.8 \pm 2.5$ & $7.7 \pm 2.5$ & 0.121 & $5.8 \pm 2.1$ & $6.8 \pm 2.1$ & 0.000 \\
\hline \multicolumn{7}{|l|}{ SF umbilicus $\left(\mathrm{cm}^{2}\right)$} \\
\hline High BP & $2.3 \pm 0.8$ & $2.8 \pm 0.8$ & 0.002 & $2.6 \pm 1.6$ & $2.6 \pm 1.2$ & $0.041^{*}$ \\
\hline Hyperglycemia & $2.4 \pm 1.4$ & $2.6 \pm 0.8$ & 0.023 & $2.6 \pm 1.7$ & $2.7 \pm 1.1$ & 0.178 \\
\hline High TG & $2.4 \pm 1.3$ & $2.6 \pm 0.7$ & 0.006 & $2.6 \pm 1.5$ & $2.8 \pm 1.4$ & 0.465 \\
\hline Low HDL & $2.5 \pm 1.2$ & $2.5 \pm 0.6$ & 0.264 & $2.7 \pm 1.9$ & $2.8 \pm 1.1$ & 0.828 \\
\hline Wide WC & $1.9 \pm 0.6$ & $2.9 \pm 1.2$ & 0.00 & $1.9 \pm 0.6$ & $2.7 \pm 1.5$ & 0.00 \\
\hline MS & $2.4 \pm 1.3$ & $2.7 \pm 0.8$ & 0.025 & $2.6 \pm 1.5$ & $2.8 \pm 1.2$ & 0.082 \\
\hline \multicolumn{7}{|l|}{ VSR umbilicus $\left(\mathrm{cm}^{2}\right)$} \\
\hline High BP & $3.1 \pm 1.2$ & $3.1 \pm 1.2$ & 0.976 & $2.5 \pm 1.2$ & $2.8 \pm 1.2$ & $0.040 *$ \\
\hline Hyperglycemia & $3.0 \pm 1.1$ & $3.2 \pm 1.2$ & 0.815 & $2.6 \pm 1.1$ & $2.6 \pm 1.2$ & 0.352 \\
\hline High TG & $3.2 \pm 1.2$ & $3 . \overline{1} \pm 1.1$ & 0.364 & $2.6 \pm 1.2$ & $2.7 \pm 1.2$ & 0.631 \\
\hline Low HDL & $3.2 \pm 1.2$ & $3.1 \pm 1.1$ & 0.702 & $2.6 \pm 1.2$ & $2.8 \pm 1.2$ & 0.524 \\
\hline Wide WC & $3.2 \pm 1.2$ & $3.1 \pm 1.2$ & 0.535 & $2.2 \pm 0.9$ & $2.7 \pm 1.2$ & $0.034 *$ \\
\hline MS & $3.1 \pm 1.2$ & $3.1 \pm 1.2$ & 0.521 & $2.5+1.1$ & $2.8+1.3$ & 0.104 \\
\hline
\end{tabular}



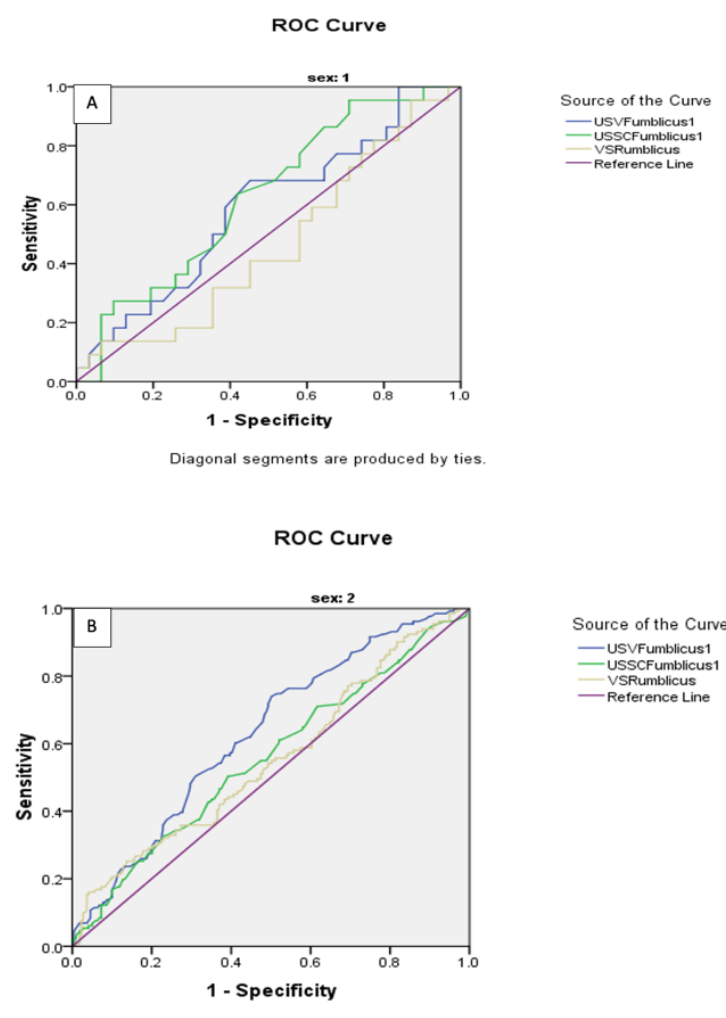

Source of the Curve —usvFumblicus1 - USSCFumblicus

Diagonal segments are produced by ties.

Fig.1. ROC curves for VAT, SAT abd VSR to predict MS among obese Egyptians: A1: among men, A2: among women.

TABLE IV:AREA UNDER THE CURVE C, D

\begin{tabular}{|c|c|c|c|c|c|c|}
\hline \multirow{2}{*}{ Sex } & \multirow{2}{*}{$\begin{array}{l}\text { Test Result } \\
\text { Variable(s) }\end{array}$} & \multirow{2}{*}{ Area } & \multirow{2}{*}{$\begin{array}{l}\text { Std. } \\
\text { Error }\end{array}$} & \multirow{2}{*}{$\begin{array}{l}\text { Asymptotic } \\
\text { Sig. }\end{array}$} & \multicolumn{2}{|c|}{$\begin{array}{c}\text { Asymptotic } 95 \% \\
\text { Confidence Interval }\end{array}$} \\
\hline & & & & & $\begin{array}{l}\text { Lower } \\
\text { Bound }\end{array}$ & $\begin{array}{l}\text { Upper } \\
\text { Bound }\end{array}$ \\
\hline \multirow{3}{*}{1} & $\begin{array}{c}\text { USVF } \\
\text { umbilicus }\end{array}$ & 0.589 & 0.056 & 0.121 & 0.479 & 0.699 \\
\hline & $\begin{array}{c}\text { USSCF } \\
\text { umbilicus }\end{array}$ & 0.628 & 0.054 & 0.025 & 0.522 & 0.734 \\
\hline & VSR umbilicus & 0.463 & 0.057 & 0.521 & 0.352 & 0.575 \\
\hline \multirow{3}{*}{2} & $\begin{array}{c}\text { USVF } \\
\text { umbilicus }\end{array}$ & 0.630 & 0.030 & 0.000 & 0.571 & 0.689 \\
\hline & $\begin{array}{c}\text { USSCF } \\
\text { umbilicus }\end{array}$ & 0.556 & 0.032 & 0.082 & 0.493 & 0.618 \\
\hline & VSR umbilicus & 0.552 & 0.032 & 0.104 & 0.489 & 0.615 \\
\hline
\end{tabular}

\section{DisCUSSION}

Obesity is a significant global health problem especially in developing countries. Body composition changes as result of obesity have a drastic effect on metabolism. Adipose tissue is designated to be a crucial factor modulating lipid and glucose biotransformation. So, the necessity to have simple and sensitive tools to assess body composition and adipose tissue thickness in particular, is particularly essential [16]. Body adipose tissue quantity itself is a risk factor; however, its distribution is a pivotal risk factor for metabolic syndrome and its related risk factors. So, determining abdominal fat content is essential for assessment obesity in susceptible personnel [17].
Regional fat compartments, including visceral and subcutaneous adipose tissues, differ in various populations. Studies in adults have revealed that visceral adipose tissue (VAT) is more firmly correlated with cardio-metabolic risk factors than total and subcutaneous adipose tissue (SAT) [1]. Subcutaneous adiposity was related to fasting insulin and sensitivity in similar subjects. This subcutaneous adiposity was higher in black compared to white inhabitants for similar levels of total adiposity. Therefore, examining differences in VAT and SAT in specific ethnic clusters may aid verification of various levels of health risks linked with obesity [18].

Therefore, the purpose of cudrrent research was to explore if VAT, SAT or VSR has diagnostic value in identifying metabolic syndrome among sample of obese adult Egyptians.

Several reviews have displayed that subject with high abdominal VSR are the most susceptible to diabetes and CVDs. In comparison with Caucasian personnel, Asian subjects are more liable to diabetes and CVDs because they have high abdominal VAT than SAT [4].

Reference [19], had found that over $40 \%$ of overweight or obese adults ageing between 18 and 50 years had MS. In a study done by [20] the prevalence of MS was documented to be increased among obese people (34.5\%) of younger age.

In the current study, inspite insignificant sex difference in the frequency of MS, $28.3 \%$ of male and $25.4 \%$ of female had 3 risk factors of MS, 9.4\% and 10.9\% had 4risk factors of MS, and $3.8 \%$ and $1.1 \%$ had 5 risk factors of MS respectively. The presence of MS might be due to significantly higher value of subcutaneous fat among men and visceral fat among women.

Increased adipose tissue distribution in the abdomen is associated with hyperinsulinaemia, and triglycerides, decreased HDL cholesterol, high blood pressure increases and increased in insulin resistance. Larger central fat deposit is also linked with less advantageous plasma lipid and lipoprotein concentrations [17].

In the existing work females had significantly superior values of SBP while male had considerably higher incidence of high triglycerides and low HDL, and insignificant higher frequency of hyperglycemia and MS.

The process regulating body adiposity dissemination stay largely ill defined, although age, gender, stress, smoking, a lack of exercise and endocrine and genetic factors have displayed a dramatic effect. Adipose tissue distribution could be taken as an indicator verifying the personal human body condition [21].

Current work compared VAT, SAT, and VSR of subjects in relationship to metabolic risk indicators and we analyzed which one of them was superior and had the screening value to anticipate several risk factors.

Reference [4] had documented that the allocation of abdominal adipose tissue may be more significant than visceral and subcutaneous adipose tissue area per se as VSR is more powerfully related to the danger of CVD than visceral adipose tissue zone.

Considering the disparity of body shape and size in between population it appears that the absolute quantity of VAT may not entirely express such distinction while deciding visceral obesity. Therefore, [22] had postulated that it is difficult to apply VAT in subjects with different body types and theoretically VSR would be a better indicator to permit assessing a person's build. 
Reference [23], and [24] research have displayed that visceral adipose tissue and VSR are linked to the advancement of diabetes and CVD. Reference [25], showed that the VSR assessed by ultrasound examination is considerably linked with glucose metabolism in patients at great risk of developing category 2 diabetes mellitus. While [4], documented that the occurrence of diabetes and hypertension was not associated with the V/S ratio.

In current study visceral and subcutaneous adipose tissue were markedly higher in presence of hypertension among both sexes. Visceral/subcutaneous fat ratio was vastly higher in presence of hypertension among women only. Moreover, subcutaneous fat was vastly higher in presence of hyperglycemia and increased triglycerides among men.

Reference [26] discovered that, in a sample of 437 individuals, the VSR was independently linked with cardiometabolic risk factor grouping in females $(n=197)$, whereas in males VAT was a better correspond of cardio-metabolic hazard than VSR. Reference [27] demonstrated that, in a Korean inhabitant, a superior VSR was linked with lower prevalence of the metabolic syndrome, higher HDLcholesterol, lower triglyceride and lower fasting glucose, even after correction for BMI.

Reference [22], documented that VSR has prognostic importance as a peculiar marker to anticipate several metabolic risks irrespective of person's age and BMI. After correction for age and BMI, mean VSRs were considerably distinct between clusters in respect to each risk factor, except for low HDL-cholesterol in males. However, mean VATs and SATs showed no great differences between groups. Moreover, the assessment value of VSR was superior to VAT in males, but similar in females. These outcomes concerned that the tendency for visceral fat deposits (as compared to subcutaneous) is associated with metabolic risks irrespective of age and BMI.

Current study concluded that MS was significantly affected by visceral and subcutaneous adipose tissue; not VSR in both sexes. Subcutaneous adipose tissue was significantly superior to visceral adipose tissue among men, while VAT was superior to SAT among women. VSR cannot be used as a predictor of MS.

Reference [28], concluded that accurate and practical methods for quantifying body adipose tissue is vital for efficient monitoring, prevention, and handling of obesity related risk factors.

\section{CONCLUSION}

Visceral and subcutaneous fat; not visceral/subcutaneous fat ratio; were significantly affected by the presence of MS in both sexes. Subcutaneous fat was significantly superior to visceral fat among men, while visceral fat was superior to subcutaneous fat $(\mathrm{P}<0.000)$ among women. Visceral/subcutaneous fat ratio cannot be used as a predictor of $\mathrm{MS}$.

\section{CONFLICT OF INTEREST}

The authors declare that there are no financial and personal relationships with other people or organizations that could inappropriately influence (bias) the present work.

\section{ACKNOWLEDGMENTS}

We would like to acknowledge our institute "National Research Centre'; Egypt"; without their support this study could not be done. Authors are also grateful to everybody participated in this study; the employers of our institute who were the participants of this study, the technicians who helped in the laboratory analysis and the doctors who participated in collection of the data'. Without their help, this study couldn't have been completed.

\section{AUTHOR CONTRIBUTION}

Nayera E.Hassan and Mohamed S. El Hussieny, designed the study; Nayera E.Hassan, supervisor on anthropological assessment; Sahar A. El-Masry performed the statistical analysis and publication process; Mohamed S. El Hussieny responsible for radiological assessment of visceral obesity and writing the first draft of the article; Enas Abdel Rasheed responsible for laboratory investigations. All authors contributed to the collection of references, drafting of the article, and final approval of the version to be submitted. All the authors have accepted responsibility for the entire content of this submitted manuscript and approved submission.

\section{REFERENCES}

[1] Yan Y, Liu J, Zhao X, Cheng H, Huang G, Mi J. Abdominal visceral and subcutaneous adipose tissues in association with cardio- metabolic risk in children and adolescents: the China Child and Adolescent Cardiovascular Health (CCACH) study. BMJ Open Diabetes Research and Care.2017; (1): e000824.

[2] Sakuno T. Tomita ML, Tomita CM, Back Giuliano I. de Carlos, Ibagy A, Perin N.Medeiros, et al.Sonographic evaluation of visceral and subcutaneous fat in obese children.Radiol.2014; 47(3).

[3] Jung C, Rhee EJ, Kwon H, Chang Y, Ryu S, Lee WY.Visceral-toSubcutaneous Abdominal Fat Ratio Is Associated with Nonalcoholic Fatty Liver Disease and Liver Fibrosis. Endocrinol Metab.2020; 35:165-176.

[4] Kwon S, Han A. The Correlation between the Ratio of Visceral Fat Area to Subcutaneous Fat Area on Computed Tomography and Lipid Accumulation Product as Indexes of Cardiovascular Risk. Journal of Obesity \& Metabolic Syndrome. 2019;28:186-193.

[5] Meuller W, Maughan RJ. The need for a novel approach to measure bodycomposition: Is ultrasound an answer? Br J Sports Med.2013;47: 1001-1002.

[6] Meuller W, Lohman TG, Stewart AD, Maughan RJ, Meyer NL, Sardinha LB, et al. Subcutaneous fat patterning in athletes: Selection of appropriate sites and standardization of a novel ultrasound measurement technique: Ad Hoc Working Group on Body Composition,Health and Performance, under the auspices of the IOC Medical Commission. Br J Sports Med. 2016; 50:45-54.

[7] Eifler RV. The role of ultrasound in the measurement of subcutaneous and visceral fat and its correlation with hepatic steatosis. Radio Bras.2013; 46(5):273-278.

[8] Hiernaux J, Tanner JM.Growth and physical studies. In J.S. Weiner, S.A. Lourie (Eds.), Human Biology: A guide to field methods. London: IBP; Oxford, UK: Blackwell Scientific Publications, 1969.

[9] WHO. Global database on Body Mass Index: BMI Classification. Geneva: World Health Organization, 2006.

[10] Ribeiro-Filho F, Faria AN, Azjen S, Zanella MT, Ferreira SR. Methods of estimation of visceral fat: advantages of ultrasonography.Obes Res.2003;11(12):1488-1494. 
[11] Allain CC, Poon LS, Chen CSG, Richmond W, Fu PC. Enzymatic determination of total serum cholesterol. Clin Chem.1974;20:470-475.

[12] Fossati P, Principe L.Serum triglycerides determination colorimetrically with an enzyme that produces hydrogen peroxide.Clin Chem.1982;28:2077-2088.

[13] Burstein M, Scholnick HR, Morfin R. Rapid method for the isolation of lipoproteins from human serum by precipitation with polyanions. $J$ Lipid Res.1970; 11:583-595.

[14] Friedewald WI, Levy RI, Fredrickson DS. Estimation of the concentration of low-density lipoprotein cholesterol in plasma without use of preparative ultracentrifuge.Clin Chem.1972;18:499-502.

[15] International Diabetes Federation. The IDF consensus worldwide definition of the metabolic syndrome. Brussels, Belgium, 2017.

[16] Chiriţă-emandi A, Camelia papa M, Abrudan L, Amelia dobrescu M,Puiu M, Velea IP, et al. A novel method for measuring subcutaneous adipose tissue using ultrasound in children - interobserver consistency. Rom J MorpholEmbryol.2017; 58(1):115-123.

[17] Jung JH,Kyung JM, Eun KK, Kwon A,WookChae H,Yoon C, et al. Ultrasound measurement of pediatric visceral fat thickness: correlations with metabolic and liver profiles. Ann Pediatr. Endocrinol Metab. 2016; 21(2): 75-80.

[18] De Lucia RE, Norris SA, Sleigh A, Brage S, Dunger D, Stolk RP, Ong K.Validation of Ultrasound Estimates of Visceral Fat in Black South African Adolescents.Obesity. 2011;19 (9):1892-1897.

[19] Al-Sarraj T, Saadi H, Volek JS, Fernandez ML. Metabolic syndrome prevalence,dietary intake, and cardiovascular risk profile among overweight and obese adults 18-50 years old from the United Arab Emirates. Metab Syndr RelatDisord. 2010;8:39-46.

[20] Al Dhaheri AS, Mohamad MN, Jarrar AH,Ohuma OE, Leila IC,Al Meqbaali TF, et al. A cross-sectional study of the prevalence of metabolic syndrome among young female Emirati adults. PLoS One. 2016; 11: e0159378.

[21] Baek J, Jung SJ, Shim J, Jeon YW, Seo E, Kim HC.Comparison of Computed Tomography-based Abdominal Adiposity Indexes as Predictors of Non-alcoholic Fatty Liver Disease among Middle-aged Korean Men and Women. J Prev Med Public Health.2020; 53(4): 256265.

[22] Oh YH,Moon JH, Ju KH, Kong MH.Visceral-to-subcutaneous fat ratio as a predictor of the multiple metabolic risk factors for subjects with normal waist circumference in Korea. Diabetes, Metabolic Syndrome and Obesity: Targets and Therapy. 2017; 10: 505-511.

[23] Kanhai DA, Kappelle LJ, van der Graaf Y, Uiterwaal CS, Visseren FL, SMART Study Group. The risk of general and abdominal adiposity in the occurrence of new vascular events and mortality in patients with various manifestations of vascular disease. Int $J$ Obes (Lond). 2012; 36:695-702.

[24] Jørgensen ME, Borch-Johnsen K, Stolk R, Bjerregaard P. Fat distribution and glucose intolerance among Greenland Inuit," DiabetesCare.2013;36:2988-2994.

[25] Philipsen A, Jørgensen ME, Vistisen D, Sandbaek A, Almdal TP, Christiansen JS, et al. Associations between ultrasound measures of abdominal fat distribution and indices of glucose metabolism in a population at high risk of type 2 diabetes: the ADDITION-PRO study. PLoS One. 2015;10:e123062.

[26] He H, Ni Y, Chen J, Zhigang Z, Jian Z, Daoyan L,et al. Sex difference in cardiometabolic risk profile and adiponectin expression in subjects with visceral fat obesity. Transl Res. 2011; 155:71-77.

[27] Kim S, Cho B, Lee H, KyojooC, Hwang S, Donghee K,et al. Distribution of abdominal visceral and subcutaneous adipose tissue and metabolic syndrome in a Korean population. Diabetes Care.2011;34:504-506.

[28] Hudda MT, Fewtrell MS,Haroun D,Lum S,William JE,Wells JCK, et al. Development and validation of a prediction model for fat mass in children and adolescents: meta-analysis using individual participant data.BMJ. 2019; 366: 14293. 